\title{
GROUNDED THEORY AND USER REQUIREMENTS: A CHALLENGE FOR QUALITATIVE RESEARCH
}

\author{
Supriya Singh \\ Kylie Cassar Bartolo \\ Christine Satchell \\ RMIT University/Smart Internet Technology Cooperative Research Centre \\ Research Development Unit \\ RMIT Business \\ Melbourne, Vic 3000 \\ Email: supriya.singh@rmit.edu.au
}

\begin{abstract}
We discuss the methodological implications of moving from grounded theory to user requirements for the design of information and communication technologies. This is a problem that is particularly acute for sociology, where theory is seen as a sufficient contribution to knowledge. Cultural theorists have potentially less of a problem moving from the cultural meaning of artefacts to design. The epistemological and methodological shifts are also narrower for the applied sciences. We submit the frameworks and sequencing of the open-ended interview need to be re-structured to ground both theory and user requirements. This is a sounder basis for detailing current and future user requirements from a social perspective.
\end{abstract}

\section{INTRODUCTION}

We place the paper within three contexts: Our User-Centred Design work in the Smart Internet Technology Cooperative Research Centre in Australia; the grounded theory approach; and the need to translate from theory to user requirements for design. This is done in the first section. In the second section we reflect on how we conducted a qualitative study about how people control their personal information and identities in relation to activities. In the third section, we move to the Young People study, detailing the use of the scenario prototype. In the fourth section we outline our approach aimed at moving beyond grounded theory to grounded design. In the fifth section we explore the shift in epistemology and methodology for sociology, applied science and cultural theory. We conclude by drawing the threads together and showing how the suggested approach can bring rigour to design within a compressed time frame.

\section{SITCRC and Discovery UCD}

Smart Internet Technology Cooperative Research Centre (SITCRC) in Australia brings together 12 Australian universities and three main corporate partners. The research program at present comprises four technical streams focusing on smart personal agents, natural adaptive user interfaces, intelligent environments and smart virtual networks. The User Environment (UE) Program overlays these technical streams to ensure the user is at the centre of the design from the very beginning. The UserCentred Design (UCD) team is part of the UE program. The aim is to develop useful and commercialisable technologies. Hence in SITCRC, we work at the intersections of the social, technological and business perspectives

In this paper we report on two projects where the UCD team is working with technologists and business partners. The Secure Identity Management Project aims to design a mobile device that incorporates users' control of personal information and identity. The UCD team conducted 17 openended interviews in Australia to see how people control personal information. The qualitative user study was supplemented by a quantitative study of 1010 broadband users. It was envisaged these 
studies would feed into the user requirements of the mobile device. The second is the Smart Internet Technology Architecture project. It has a Swarm phone at the centre of the architecture. The Swarm phone concept was based on a qualitative study of young people's use of mobile phones (Satchell 2003).

In both projects we are still at the discovery stage of UCD (Singh et al. 2003). A mock-up of a possible design is still to be constructed. We are at the point where discussions with technologists are continuing. Though all design projects are distinctive, our projects differ from those usually described in the UCD literature in two ways. Firstly, we are working outside a single organizational context, with our members drawn from academia and industry in three Australian cities. It has made possible a more extensive user study than is usually found in strictly commercial projects. However, there has been a sharper division of labour than we would have liked, between the UCD and technical people of our projects. In this context, reflection about methodology aids the process of team formation. This is also important within the UCD team, which comprises a social anthropologist, a psychologist and a communications researcher. In the UCD team we have worked closely with one of our business partners who is also a psychologist.

Secondly, in both projects we are considering issues like "privacy", "identity" and "social networks" which go beyond the organizational boundaries implicit in much of UCD and Human Computer Interaction (HCI) literature. The social and cultural context becomes an important framework for the analysis of attitudes and behaviour. So in working out a methodology that has relevance for design, we need to be participant observers of our own project (Singh et al. 2004)

\section{Grounded theory}

Grounded theory emphasises the fit between data and the emerging theory, rather than moving deductively down from a prior hypothesis (Glaser 1978; Glaser and Strauss 1967; Strauss and Corbin 1990). The emergence of theory from data is one of the defining elements of qualitative research As Morse and Richards (2002) say, "All qualitative research seeks understanding of data that are complex and can be approached only in context" (Morse and Richards 2002).

The literature on grounded theory differs as to how the analysis helps themes to emerge from the data. We have detailed our approach as we discuss the analysis of data in our two projects. Following Charmaz (2000), we do not use grounded theory to discover an objective reality, but as "flexible, heuristic strategies" (Charmaz 2000, p. 510)to understand and interpret empirical worlds in their multiplicity and relativity.

\section{The translation process}

The focus on translation is important, for the grounded study of use does not necessarily lead to viable design concepts. As Beyer and Holtzblatt (1998) say, "Design is a cognitive activity. It is thought work. It begins with a creative leap from customer data to the implications for design and from implications to ideas for specific features. A clear understanding of the customer doesn't guarantee any kind of useful system gets designed and delivered. Design depends on being able to see the implications of data" (Beyer \& Holtzblatt, 1998, p. 16).

This opaqueness between user data, design, and business value is because of three reasons. Firstly, users do not always know what they want. Karen Holtzblatt tells how she wanted windows in her den. But what she really wanted was a lot of light to see the garden (Beyer \& Holtzblatt, 1998). The second reason for the lack of seamlessness in the process is that there is often a division of labour the user study being done by social scientists while the design concepts are in the hands of the technologists (Button, 2003). The business dimension often comes later. The third difficulty of 
translating user data into design is the "socio-technical gap" (Ackerman, 2002). Ackerman says one of the challenges of Human Computer Interaction (HCI) is to build technical systems that support the social world in all its nuances and contexts.

\section{THE USER STUDY: SECURE IDENTITY MANAGEMENT PROJECT}

In this section we reflect on how we conducted a qualitative study about the way people control their personal information and manage their identities for different activities within a social and cultural context. Our activity focus shared much with "activity theory" which has its origins in psychology. We have the same emphasis on a "web of activities" (Bertelsen and Bødker 2003), rather than assume a linear, sequential structure. We also drew on studies of the social shaping of technology to investigate how technologies shape and are shaped by social relations and cultural values.

It was clear from the outset we were conducting the user study to feed into the design of mobile devices with privacy mechanisms. However, we followed standard grounded theory procedures both in the conduct of the interview and the analysis of data for emerging theory. This meant that understandings of emerging theory were confirmed with participants during the interview and analysis. The interviews were transcribed and coded, using N6, a computer program for the analysis of qualitative data. As we were working in a team and came from different perspectives, we did broad coding. We coded at the activity and technology levels. The data were further analysed through the use of matrices. It is at this level that detailed patterns in the data emerged and led to initial explanations of the control of personal information.

The grounded theory approach to analysis emphasises transcription and coding. This means that an hour of interview takes roughly four hours of transcription and around ten hours of analysis. It is a time intensive way of doing user research, particularly if we add the required meetings within the UCD team, and meetings with our technological and business partners.

We thought the resulting rigour of the theory was worth it. Firstly our study went deeper into the users' perspective of the control of personal information than policy directed surveys, or technological studies of privacy. Policy directed surveys tend to emphasise the importance of the value of privacy, without necessarily illustrating how people deal with information about different activities in various contexts. Technological studies of privacy emphasise the need for withholding disclosure with pseudonymity and anonymity being along the spectrum of privacy.

In contrast to previous studies, our user study led us to three main theoretical conclusions that are important for the design of all information and communication technologies (Singh and CassarBartolo 2004). The first was that people saw privacy was about sharing personal information with people of their choice using the channels they preferred for the particular activity and audience.

Secondly, people shared personal information relating to money and health in different ways within the same social and cultural context. These conclusions became apparent during the data collection and analysis stages. We had particularly asked about control of personal information for different activities. As money and health emerged as the two of the most private areas, the focus was on how they shared information with their partners, close friends and family and others.

The third cluster of theory revolved around connecting yet disentangling the concepts of privacy, identity, security and trust. The link was that of "user control". However the centrality of user control not only for privacy and identity, but also for security and trust, emerged only in the analysis stage. Hence there was "missing data" about the precise nature of that control. Missing data however is a common occurrence in qualitative research (Singh and Richards 2003) and indeed in all scientific research where one problem leads to the articulation of another (Popper 1979).

It was another kind of missing data with which we became more concerned. We had not tested the scenarios and user requirements - required for design workshops with the technologists in the 
project team - in the same way that we had sought to confirm our understandings of theory. We had sufficient data from the user study to flesh out personas with sufficient knowledge behind us. However, the process of moving from data to scenario revealed gaps. These gaps were filled by previous work, particularly in the field of money and health. We came to feel we could have elicited more grounded data on the future design of mobile devices in the interviews. Recognising it is difficult to get people to speak of future design, we felt we could at least have asked them what they liked about current design, particularly as it related to user control. Presenting scenarios to them, incorporating their own experience, may have been one way of getting more valuable data on user requirements. Of course, more interviews or focus groups could have been conducted addressing these problems, but there were time and resource constraints.

Let us illustrate how we translated the user data to scenarios. This process meant going from the broad conclusions about personal information to how one person dealt with his or her personal information in a particular activity and social context. At the broadest level, our theory was that people want to control their personal information in terms of channel, audience, content, and context. Personal communication, finance and health are particularly sensitive areas in Anglo-Celtic Australia. Yet people control the information differently according to activity. In terms of channel, the telephone is seen as the most private digital device with the Web being the least private.

These conclusions are too broad and general for design or business. They are valuable for without this kind of information, designers run the risk of designing uniformly for different activities. However, by itself alone, this kind of theory does not lead to a business or design outcome. We need to dig narrower to answer the unasked "So what?" question.

Our first instinct was to place the emerging findings in one column of the table and side by side present the design and business implications. But we found we needed to re-cast the scope of the findings to come to usable starting points. Scenarios not only worked as a communication tool, but also as a mode of translation. This is because the scenario presents the persona, the context and the way an activity is performed. It then extracts the user problem, and suggests a possible design approach.

In this user study, for the privacy of money, we focused on Joe, 65, who pays his bills via the phone. We had to go through four steps. First, we narrowed the wider field of money to payments and money management. It is important to have this "web of activities" for the success of a payments technology often depends on its success for money management. Second, the telephone was chosen as the channel from all the possible options, not only because the phone is seen as most private, but because the emphasis of the project was on mobile devices. Paying by phone was also pertinent to our business partners. Third, we articulated the user problem that paying bills by phone is repetitive and time consuming. Fourth, we put forward the design suggestion that the customer number and credit card details relevant for specified merchants be stored, to automate part of the process. We noted that to ensure control, the user needs to confirm the transaction for it to be valid. We also suggested that an e-mail be sent so that a paper record is possible. The format of this record should be compatible with personal financial management programs.

The scenario captures only one part of the user study and its conclusions. In capturing the specifics of one persona and activity; elucidating the user problem; and suggesting an acceptable design solution - the user study becomes relevant for designers and businesses. The two processes however differed in terms of rigour. It was as if we made an intuitive jump to go from theory to design. We could not point to the data that underlay the precise detail of the scenario. Some of the detail came from everyday knowledge. Some of it came from prior study of money and channels of communication. However, it would have been more in the character of a rigorous user study if the scenario and user requirements had been a parallel subject of conversation and examination, when the interviews were being conducted. 
Prior theory and literature

Open ended interviews - grounded theory of use

Analysis stage - Grounded theory, preliminary scenarios and social user requirements

Workshopped ideas with technologists and business partners

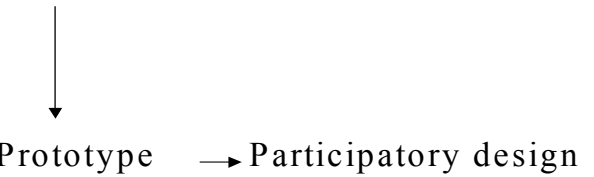

Figure 1: Open-ended interviews: Process of moving from theory to design

YOUNG PEOPLE STUDY: USER STUDY AND THE SCENARIO PROTOTYPE

The Young People study had a different sequence. It was conducted as part of a PhD. Like the user study for the Secure Identity Management Project, this was a grounded study that produced theory about young people's use of Information and communication technologies. The methods for theory production were as described In the section above.

Discussions with technologists and business partners began after data collection and preliminary theory analysis. Scenarios were presented to technologists at workshops and repeatedly modified by going back to a select group of users, and then back to the technologists. The Swarm scenario was returned to selected users in the study three times over an 18 month period. This initially happened to ensure the rigour of the scenario. It was interesting to note that the scenario generated in-depth user responses, and produced a high level of user feedback. The scenario thus was effective not only for communicating with computer scientists but as means of gathering extra user requirements, thereby filling in the gaps left by the open-ended interviews. Each time the Swarm was modified to reflect their needs. For example, the users' initial desire was to be able to control who called them and when, this lead to the development of avatars so that a digital representation of could be programmed to act for the user. Yet when revisiting the scenario the users stated that while this level of control was a desirable feature - it should be just that - a feature. There were times when you wanted a lot of control over who called you but at other times you didn't want to have to have that level of involvement with the phone. Hence, the Swarm is now being modified with the addition of a default mode that indicates the user as either at work/university/school or at home.

The modified scenarios were then taken back to the technologists. The discussion then was to convert the social user requirements to technical user requirements and then a prototype. The process is depicted in figure 2 . The process has worked well in that the scenarios generated by this user study for a Swarm phone have become the key scenarios in at least two of the technological projects. But we are also conscious that at least a year's work had been completed in the user study 
and that there had been sufficient attention paid to theory before the work on scenarios began. This kind of extensive user study is possible within a three-year time span, but is unlikely to be the norm for most user-centred design.

Prior theory and literature

Open ended interviews - grounded theory of use

Analysis stage - Grounded theory and preliminary scenarios and social user requirements

Workshopped ideas with technologists and business partners

- Go back to users with scenario prototype

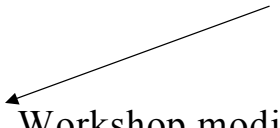

Workshop modified SP with technologists and business partners

$\downarrow$ Prototype $\longrightarrow$ Participatory design

Figure 2: The open-ended interview and the scenario prototype

\section{GROUNDED THEORY AND USER REQUIREMENTS: THE NEW APPROACH}

Based on our experience we suggest two modifications to qualitative research which aims to lead to both grounded theory and grounded user requirements design.

Firstly, the preparation for the qualitative research should not only include prior theory, but also some preliminary scenarios. This will enable the Interviewer to follow up theory understandings with a confirmation of the adequacy of the preliminary scenarios. It is difficult for a person to articulate what he or she would like In the future from a technology that is still to be designed. Showing a person a mock-up of future technology, can lead the participant to couch all the answers in that framework. However when a story is presented to the interviewee, it is easier to say whether the story rings true or not. In the discussion, the story gets modified, so that it is true to the social context of the activity. The scenario is also a way of communicating user understandings to the technologists and business partners, so that they keep the users at the centre of design.

The second difference is that within the same open-ended Interview, the Interviewer checks the participant's view of the user requirements for future design. If a research objective of UCD is evidence-based applications, then the exploration and validation of applications must be an integral part of data collection. This will mean checking with the participant, his or her requirements of desirable design. It would add another layer to the Interview process to end up with social user 
requirements. It will cut down the need to go back repeatedly to users, before the design of the prototype. This will help with the timeliness of the user study.

We outline the process in figure 3. In figure 4 we summarise the difference between the process followed In the two user studies described above and the process we are suggesting In this section. These changes of process will require a shift in methodology and epistemology. We see the main difficulty is to overcome social science perspectives to go beyond theory to application at the broadest level.

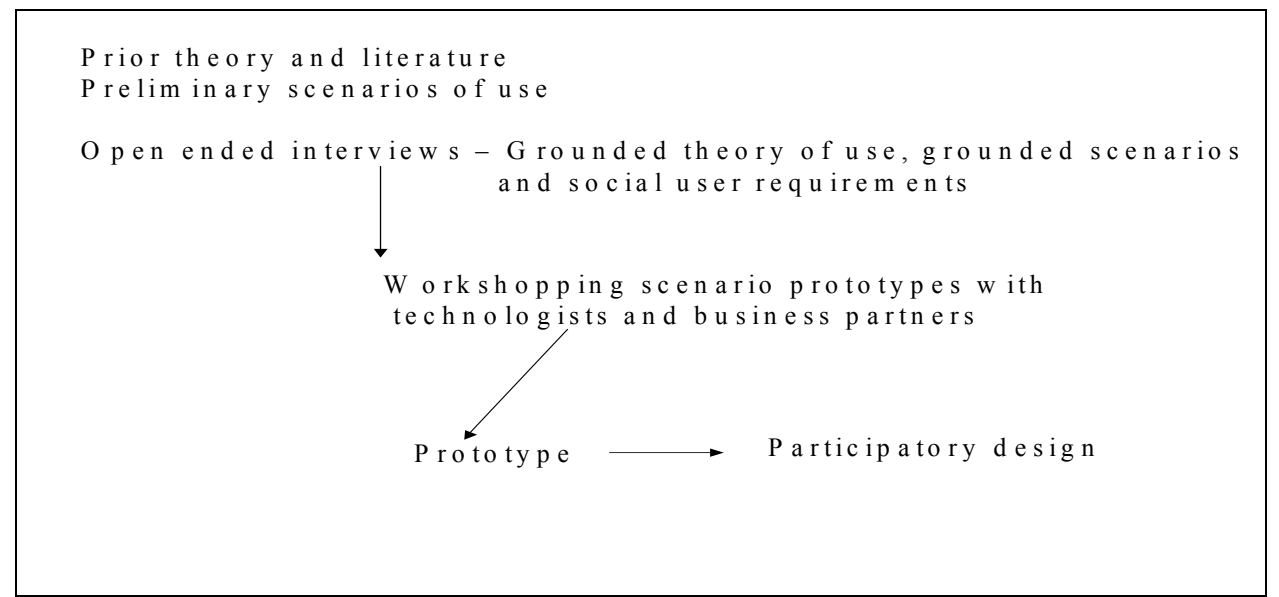

Figure 3: Qualitative research: Grounded theory and requirements

\begin{tabular}{|c|c|c|c|}
\hline Qualitative process & $\begin{array}{l}\text { The Secure Identity } \\
\text { Project }\end{array}$ & $\begin{array}{l}\text { The Young People } \\
\text { Study }\end{array}$ & $\begin{array}{l}\text { Grounded theory and } \\
\text { requirements } \\
\text { approach }\end{array}$ \\
\hline $\begin{array}{l}\text { Preparing for } \\
\text { interviews }\end{array}$ & $\begin{array}{l}\text { Prior theory and } \\
\text { literature }\end{array}$ & $\begin{array}{l}\text { Prior theory and } \\
\text { literature }\end{array}$ & $\begin{array}{l}\text { Prior theory and } \\
\text { literature } \\
\text { Preliminary scenarios } \\
\text { of use }\end{array}$ \\
\hline $\begin{array}{l}\text { Data collection via } \\
\text { open-ended interviews }\end{array}$ & $\begin{array}{l}\text { Grounded theory of } \\
\text { use }\end{array}$ & $\begin{array}{l}\text { Grounded theory of } \\
\text { use }\end{array}$ & $\begin{array}{l}\text { Grounded theory of } \\
\text { use, scenarios and } \\
\text { preliminary social user } \\
\text { requirements }\end{array}$ \\
\hline Data analysis & $\begin{array}{l}\text { Theory, preliminary } \\
\text { scenarios and social } \\
\text { user requirements }\end{array}$ & $\begin{array}{l}\text { Theory, preliminary } \\
\text { scenarios and social } \\
\text { user requirements }\end{array}$ & $\begin{array}{l}\text { Grounded theory, } \\
\text { grounded scenarios } \\
\text { and social user } \\
\text { requirements }\end{array}$ \\
\hline $\begin{array}{l}\text { Workshops with } \\
\text { technologists }\end{array}$ & $\begin{array}{l}\text { Scenarios, } \\
\text { connecting social } \\
\text { and technical user } \\
\text { requirements }\end{array}$ & $\begin{array}{l}\text { Scenarios, connecting } \\
\text { social and technical } \\
\text { user requirements }\end{array}$ & $\begin{array}{l}\text { Scenario prototypes, } \\
\text { connecting social and } \\
\text { technical user } \\
\text { requirements }\end{array}$ \\
\hline Going back to users & $\begin{array}{l}\text { Not reached that } \\
\text { stage yet }\end{array}$ & $\begin{array}{l}\text { Present and modify } \\
\text { scenario prototypes }\end{array}$ & Not required \\
\hline
\end{tabular}




\begin{tabular}{|l|l|l|l|}
\hline $\begin{array}{l}\text { Prototype and } \\
\text { Participatory design }\end{array}$ & $\begin{array}{l}\text { Going back to users } \\
\text { with technologists } \\
\text { observing }\end{array}$ & $\begin{array}{l}\text { Going back to users } \\
\text { with technologists } \\
\text { observing }\end{array}$ & $\begin{array}{l}\text { Going back to users } \\
\text { with technologists } \\
\text { observing }\end{array}$ \\
\hline
\end{tabular}

Figure 4: Grounded theory and user requirements

\section{SHIFT IN EPISTEMOLOGY AND METHODOLOGY}

The new grounded theory and user requirements approach requires a continuum between theory and practice. Both theory and practice are important. Theory can lead to a better concept of practice and exploration of practical applications can lead to a better theory. However, this connection between theory and practice is not automatic for each has a different tradition of knowing. This gap is particularly evident in the disciplinary frameworks of sociology and anthropology. It is difficult to reconcile the social science focus on theory to the particularities of the current and future design of technologies. The gap between theory and practice is also present in the applied sciences like engineering and psychology. Though there is an assumption within the applied sciences that sound theoretical conclusions will lead to good practice, bridging theory and practice is a discrete and conscious step in itself. Cultural theory has seldom been used for design but with its emphasis on meanings of artefacts slides more easily between theory and design.

\section{Sociology's tussle with UCD}

The aim of sociological studies is to arrive at rigorous theory, which can explain social phenomenon. There has been important work which has argued that technologies shape and are shaped by social relations and cultural values (MacKenzie and Wajcman 1999). Another stream of sociology has dealt with situated action and everyday life (Goffman 1959 ,Suchman 1987). These frameworks are valuable for the design of technologies, for they focus on the way technologies are used within social and cultural contexts. It is a needed corrective to much of the Human Computer Interaction (HCI) literature where the focus is often on an individual interacting with a machine.

The empirical traditions of sociology and anthropology have been used with good effect in HCI to present the context of use, as with contextual inquiry (Beyer and Holtzblatt 1998). But as Button (2003) says, particularly of the ethnographic approach in studying work practices, "ethnography in HCI has really stood as a proxy for 'fieldwork,' grounded, we could add, in ethnomethodology" (p. 364). Fieldwork in HCI and Anthropology try and get an understanding of the worlds of the user. However, in HCI, the emphasis is on getting a quick appreciation of the context, whereas Anthropology demands a long immersion and at the same time, a distance from the people being studied. While some observation is better than none, as Carroll (2003) says, there is currently a prevalence of "quick and dirty" (p. 1) ethnography, without enough theoretical reflection.

Though the methods of anthropological inquiry have been embraced by HCI, with looser standards of rigour, the theoretical frameworks of anthropology do not translate so easily to design. In anthropology, there remains a colonial bias against telling people how they should live. When computer scientists Sommerville, Rodden and Sawyer reflected on their collaboration with sociologists in a project on automating aspects of an airport system, they said sociologists had contributed to the technological approach to systems development by being

....the users' champion and the designer's conscience. As the users' champion, the sociologists tell developers about the actual work practice and the users' perception of this work practice. This input is provided formally by the development of field notes which document the observations of the sociologists and less formally by the use of debriefing meetings where system developers question the ethnographer. " (p. 346) 
They also identified three problems. The first was that sociologists were more used to asking questions and observing, than formulating solutions. As (Sommerville et al. 1992)) say,

Sociologists are not usually concerned with discovering improved ways of carrying out a task, with devising techniques and methods for supporting a particular set of behaviours or with inventing new ways of tackling a particular problem. They work very hard to avoid being classed as social engineers who pose 'solutions' to observed social problems (p. 351). The second was the time-consuming aspect of interacting with sociologists through their field notes and workshops. The third was that sociologists concentrated on the whole, whereas computer scientists needed to make decisions about individual tasks that should or should not be supported in the automated system. They say

The key to building better systems is not to avoid making judgements but to bring in appropriate expertise so that decisions are better informed. Our sociologist collaborators have now recognised that we can only build imperfect systems and that they cannot opt out of making judgements about the process which they are studying (p. 347).

Sommerville et al's collaboration with sociologists was fruitful overall. However, in the process, sociologists had to give up some of their long held ways of working, so as to contribute to the emerging design. Their approach was to work in parallel, with both the design and the user study emerging at the same time.

\section{Applied sciences: The case of psychology and engineering}

Practice is the desired outcome of good theory in the applied sciences. Of central concern to practicing psychologists is providing efficacious psychological services. Hence the dominant rationale underlying psychological research is the scientist-practitioner model - evaluating theory and applications against client outcomes and good practice. In applied psychology there is an acknowledgement that practice needs to have an empirical basis. However the path between research conclusions and psychologists applying evidence-based practices remains problematic. Recently there has been a questioning of the scientist-practitioner model - does it polarise psychological theory and practice? Is there a need for another more process-focused model to clarify how psychologists can learn from research conclusions and apply evidence-based practices (see Lunt 1994, 2000)?

In order to explore and validate design applications there needs to be a shift in epistemology. A difficulty with this more refined epistemology of practice in engineering is the split between theorists and technological designers. Schmid (2001) says,

Theorists and designers have two fundamentally different thinking styles. For a designer, every new project starts with chaos, he or she is used to gaining experience until he or she achieves sufficient...[techniques]...to solve the problem. For the designer, immediate appearance, sensory evidence, and experience are the most important sources of knowledge, and theories are just tools, like maps to a hill-walker, which give a rough impression of where to go but do not tell when and how one has to jump over a rock...Theorists are different. For them, the theories are the most important elements of science, and their most valued sources of knowledge are tradition, analogy, theoretical beauty, and logical reasoning. They are like birds, for whom the map used by the hillwalker is more than detailed enough, and who only dive down to look at details in places that look promising on the map. They often do a systematic search for such places. If theorists discuss design, they start from theories and incorporate more and more nonidealities to approach reality (Schmid 2001, p.109). 


\section{Cultural theory}

Cultural theory is rarely used for design and is not known for its empirical traditions. However, when cultural theory frameworks are used for empirical work, our work shows that cultural theory provides a useful framework for conducting and analyzing user studies and then translating the findings into design. This is because cultural theory is not only concerned with how the users interact with technologies but of the meanings that these interactions brings.

There is a shared agreement amongst cultural theorists that technology is one of the defining discourses of our time, regardless of whether they are utopian (Haraway 2001) or distopian (Baudrillard 1983, 1995). Both critiques place much importance on the power of the technological artefact as a cultural signifier so the incredible range of meanings that interactions with technologies brings are explored.

Cultural theory also provides a framework for understanding how users can be liberated through their interactions with digital technology. This is because they examine how digital technologies collapse currently held notions of time and space (Baudrillard 1995, Jameson 1991, Rheingold 1993) allowing the user to freely traverse digital landscapes (Deleuze and Guatarri 1987). Furthermore, Haraway provides an understanding of how new technologies provide a space where users can recreate their identity free from the constructs of Western ideas of beauty, gender and sexuality.

When it comes to translating user studies into design, cultural theory provides insights into not only what users are doing but why they are doing it. It helps construct scenarios which envision a technological artefact that allows the users achieve not only their technical but their cultural goals. In the case of the Swarm scenario discussed above, it meant that the scenario was constructed to meet not only the users' technological needs but their cultural ones as well. For example, the data from the Young People study revealed that users texted their friends constantly and even when they had nothing specific to say, they just liked to broadcast that they were engaged in a specific activity. A cultural theory analysis helps to understand this in terms of the nature of virtual worlds, (Rheingold, 1993) where the boundaries between real and virtual have been eroded and a virtual interaction can be just as rewarding as a face-to-face interaction. Thinking of user behaviours in this way lead to the development of the Swarm scenario which depicted a mobile phone that had a virtual lounge room in it where users maintained a constant virtual presence. As the virtual lounge room was populated with avatars that depicted them as being involved in a particular activity, users are always able to communicate to others what they doing. The decision to use avatars was arrived at through cultural theory. Users in the study mentioned that one of the fun parts of gaming was choosing an avatar through which to represent yourself. At face value this might not have seemed to have design implications for the Swarm. The decision however, was influenced by Haraway's argument that the benefit of new technology is that you can re-construct your identity as you choose.

Another example was that users in the study revealed they liked to share digital pictures. Again a cultural theory framework helped understand this concept in terms of Baudrillard's (1983) hyper reality, in that the creation, distribution and consumption of an experience can be as valuable if not more valuable than the experience itself. Therefore the Swarm scenario depicts users being able to use the video features on the phone to capture images and display them on the walls of their virtual lounge room, so those who are not there can still share in the experience.

\section{CONCLUSION}

Our challenge in UCD is to have theory and design inform each other, to produce rigorous research and effective and timely design. This is our problem. Addressing this problem is no easy feat for it needs shifts in epistemology and methodology. Epistemologically, we combine the approaches 
from multiple areas of study so that theory slides into practice.

- Sociology provides a means to build detailed relevant theory, particularly understandings of social contexts. What is needed is an emphasis on design.

- The applied sciences provide the beginnings of research method that empirically connects theory to practice.

- Studies of cultural theory possibly provide a theoretical basis that translates more easily to design, specifically understanding the meanings of cultural artefacts for people.

- Human Computer Interaction addresses design issues directly.

Methodologically, we have sought to combine the empirical techniques of sociology and anthropology with a more grounded approach, not only to theory but to design. We have done this by combining the body of knowledge about qualitative research with the value of scenarios and personas as a methodology for design. These different disciplinary frameworks lead us to a view of qualitative research which provides grounded theory, and a way of situating design via dialogue within the world of the user.

Our grounded theory and user requirements approach synthesises these frameworks and techniques in the following two components:

- Preparation for the qualitative research should not only include prior theory, but also some preliminary scenarios. The interviewer can confirm the adequacy of preliminary scenarios with the user.

- Within the one-off open-ended interview, the interviewer checks the participant's view of the user requirements for future design to explore and validate design applications during the stage of data collection. This will help with the timeliness of the user study.

If the objective is rigorous design and research, it is not enough to be a bird or a hill-walker. One needs to be an aviation explorer, willing to capture the bird's eye view and dive down to walk and get a closer experiential look.

\section{REFERENCES}

Ackerman, M. S. (2002). The Intellectual Challenge of Cscw: The Gap between Social Requirements and Technical Feasibility. In J. M. Carroll (Ed.), Human-Computer Interaction in the New Millennium (pp. 303-324). New York: ACM Press.

Baudrillard, J. (1983). The Ecstasy of Communication In H Forster, ed, The Anti Aesthetic Essays on Post Modern Culture. Seattle: Bay Press.

Baudrillard, J. (1985) Selected Writings. 1985. In Jean Baudrillard Selected Writings. Ed. M. Poster. Cambridge: Polity.

Baudrillard, J. (1995). The Gulf War did not Take Place. trans. P. Parron. New South Wales: Power Publications.

Bertelsen, O. W. and Bødker, S. (2003). Activity theory. In J. M. Carroll (Ed.), HCI Models, Theories, and Frameworks: Toward a multidisciplinary science (pp. 291-356).

Beyer, H., and Holtzblatt, K. (1998). Contextual Design: Defining Customer-Centered Systems. San Francisco: Morgan Kaufmann Publishers, Inc.

Button, G. (2003). Studies of Work in Human-Computer Interaction. In J. M. Carroll (Ed.), HCI Models, Theories, and Frameworks: Toward a Multidisciplinary Science (pp. 357-380). Sydney: Morgan Kaufmann Publishers.

Carroll, J. M. (2003). Introduction: Toward a multidisciplinary science of human-computer interaction. In J. M. Carroll (Ed.), HCI Models, Theories and Frameworks: Toward a 
Multidisciplinary Science (pp. 1-10). Sydney: Morgan Kaufmann Publishers.

Charmaz, C. (2000). Grounded theory: Objectivist and Constructivist Methods. In N. K. Denzin and Y. S. Lincoln (Eds.), Handbook of Qualitative Research (Second ed., pp. 509-535). London: Sage Publications.

Deleuze, G. and Guattari, F. (1987). A Thousand Plateaus; Capitalism and Schizophrenia. Translated by B. Massumi. Minneapolis:University of Minnesota Press.

Glaser, B. G. (1978) Theoretical sensitivity: Advances in the methodology of grounded theory, Sociology Press, Mill Valley, CA.

Glaser, B. G. and Strauss, A. L. (1967) The discovery of grounded theory: Strategies for qualitative research, Aldine, Chicago.

Goffman, Erving. (1959) The Presentation of Self in Everyday Life. Garden City, New York: Doubleday.

Haraway, Donna (1991). Simians, Cyborgs and Women; The Reinvention of Nature. London: Free Association Books.

Jameson, F. 1991. Post Modernism, or, the Cultural Logic of Late Capitalism. Verso. London.

Lewis, J. (2002) Cultural Studies. The Basics, Sage Publications Ltd, London.

Lunt, I. and Majors. K. (2000), The professionalism of educational psychology, Educational Psychology in Practice, 15(4), 237-35.

Lunt, I. (1994). Science and practice in the education and training of psychologists. Paper presented at the $23^{\text {rd }}$ International Congress of Applied Psychology 1994, Madrid, $17^{\text {th }}-22^{\text {nd }}$ of July.

MacKenzie, D., and Wajcman, J. (Eds.). (1999). The Social Shaping of Technology (Second ed.). Buckingham: Open University Press.

Mao, J.Y., Vredenburg, K., Smith, P. W., and Carey, T. (2001). User-Centered Design Methods in Practice: A survey of the state of the Art. Paper presented at the Center For Advanced Studies Conference, http://www.cas.ibm.com/archives/2001/proceed/cascon01/pdf/mao.pdf on $24 / 2 / 2002$.

Morse, J. M. and Richards, L. (2002) Readme First for a User's Guide to Qualitative Methods, Sage Publications, Thousand Oaks, Calif.

Popper, K. (1979). Objective Knowledge: An Evolutionary Approach. Revised edition. Oxford: Oxford University Press.

Rheingold, H. 1993. The Virtual Community: Homesteading on the Virtual Frontier. Addison Wesley. Reading, MA

Satchell, C. (2003) The Swarm: Facilitating Fluidity and Control in Young People's Use of Mobile Phones. In OzCHI Brisbane, Australia.

Satchell, C. and Singh, S. (2004) User Problem - Design Solution - Swarms for Nomads. Work in Progress.

Schmid, H. (2001) Theory and practice: thinking styles in engineering and science. Australian Journal of

Information Systems, Special Issue on knowledge management, 106-115.

Singh, S., Burke, J., et al. (2003). The Discovery Phase of User-Centred Design: Putting Users First in the Design of Smart Internet Technologies. The Australasian Conference on Information Systems, Perth, School of Management Information Systems, Edith Cowan University.

Singh, S. and Cassar-Bartolo, K. (2004) The privacy of money and health, Paper to be presented at the OZCHI, Wollongong, November 22-24.

Singh, S. and Richards, L. (2003) Missing data: Finding 'central' themes in qualitative research, Qualitative Research Journal, 3,(1), 5-17.

Singh, S. and Zic, J. and Satchell, C. and Bartolo, K. C. and Snare, J. and Fabre, J. (2004) A 
Reflection on Translation Issues in User-Centred Design, Paper presented at the 7 th International Conference on Work with Computing Systems, WWCS 2004, Kuala Lumpur. Sommerville, I. and Rodden, T. and Sawyer, P. (1992) Sociologists can be surprisingly useful in interactive systems design, Paper presented at the HCI'92.

Strauss, A. and Corbin, J. (1990) Basics of qualitative research: Grounded theory procedures and techniques, Sage Publications, Newbury Park, Calif

Suchman, L. (1987). Plans and Situated Actions. Cambridge: Cambridge University Press.

\section{ACKNOWLEDGEMENTS}

We would like to acknowledge the support of our colleagues at the Smart Internet Technology Cooperative Research Centre. In particular, we would like to acknowledge the help of Dr John Zic who lead the Secure Identity Management Project. We would also like to note the importance of the discussions with Dr. John Fabre from Telstra and John Snare from Adacel who were also part of the Secure Identity Management Project.

\section{COPYRIGHT}

Supriya Singh, Kylie Cassar Bartolo and Christine Satchell (C) 2004. The author/s assign Griffith University a non-exclusive license to use this document for personal use provided that the article is used in full and this copyright statement is reproduced. The authors also grant a non-exclusive license to Griffith University to publish this document in full in the Conference Proceedings. Such documents may be published on the World Wide Web, CD-ROM, in printed form, and on mirror sites on the World Wide Web. Any other usage is prohibited without the express permission of the authors. 